\title{
THE STAGES AND GUIDLINES OF RESTRUCTURING OF THE SYSTEM OF TRADE MISSION OF THE RUSSIAN FEDERATION
}

\author{
A.Pakhomov
}

Trade missions (TM) in foreign states are an integral part of the system of promotion and protection of national economic interests and implementation of the country's foreign economic policy, while by their status they are a part of the diplomatic mission of the Russian Federation abroad. In the past 10 years, efforts have been repeatedly taken to reform the system of TM in order to upgrade its efficiency for the country's foreign complex as a whole. It is to be noted that principally different options ranging from a transfer of the foreign administrative apparatus of the Ministry of Economic Development of the Russian Federation to another agency to complete liquidation of that institution were considered.

From the early 1990s, trade missions have gone through a complex stage of transformations: from an institution which in the Soviet period carried out control over the state monopoly of the foreign trade (virtually all the spheres of foreign economic relations) in the host state to an entity which is to render diversified assistance to multiple participants in foreign economic activities (FEA) in market conditions.

Obviously, lots of problems which require a solution have amassed in the course of such transformations in TM operations. As seen from the practice, until now TM are not able to render to the full extent assistance to FEA participants, primarily, in promotion of Russian export goods and services, including high-tech ones and stimulate attraction of direct foreign investments and advanced competence to Russia.

The factors behind that are resource-related and structural limitations on TM activities, as well as system-based problems of operation of other state institutions in the foreign economic sphere. Establishment of the complete system of comprehensive support of export in Russia, upgrading of management and regulation of FEA and success in economic modernization of the country as a whole depend greatly on effective solution of those problems.

In the past 10 years, efforts have repeatedly been taken to reform the system of TM in order to promote its efficiency for the country's foreign economic complex, as a whole. It is to be noted that principally different options ranging from a transfer of the foreign administrative apparatus of the Ministry of Economic Development of the Russian Federation to another agency to complete liquidation of that institution were considered.

So, the starting point in the reforms of the TM system was the so-called "optimization" in the mid2005 when over $50 \%$ of TM and the trade commissioner's offices (TCO) at the embassies of the Russian
Federation were closed ${ }^{1}$. As a result 46 TM were preserved and three more ATC upgraded to the status of TM. Also, other Russian diplomatic missions and nongovernment entities dealing with individual issues of trade and economic cooperation with foreign states operate abroad ${ }^{2}$.

It is to be noted that lack of TM narrows greatly the opportunities of expansion of Russia's economic relations in a specific state (though there are exceptions). By virtue of orientation to their traditional functions and shortage of personnel which has work experience in the foreign economic activities, embassies of the Russian Federation cannot compensate properly that work in a host country.

In the same period, in restructuring of TM an emphasis was made on expansion of directive planning and complication of reporting on their activities by baseline indices (growth in trade volume, export and attraction of direct foreign investments to Russia) with toughening of control over fulfilment of decisions (up to personal responsibility of the administration of TM on the basis of KPI). However, such an approach underpinned by administrative measures alone failed to yield the expected results.

At the next stage in the 2008-2009 period, efforts were made to integrate TM in the general system of planning and management of the sector within the frameworks of implementation of the Foreign Economic Strategy of the Russian Federation till 2020. The system of reporting of TM was made simple and

1 Resolution No.401 of 27 June 2005 of the Government of the Russian Federation on Optimization of the System of Trade Missions of the Russian Federation in Foreign States which approves the Statute on a Trade Mission of the Russian Federation in a Foreign State.

2 At present, there are abroad over 150 embassies of the Russian Federation, 4 permanent representative offices of the Russian Federation (Missions) with international economic organizations and 15 representative offices of the Chamber of Commerce and Industry and a number of other entities. 
some outdated competences were liquidated, while the emphasis was made on promising lines of development of Russia's foreign economic relations and support of large international projects ${ }^{1}$. However, the consequences of the world crisis and the need to deal with domestic economic problems prevented that development.

In the post-crisis period, further restructuring of TM was expected to be carried out primarily with utilization of program and purpose methods. In particular, within the frameworks of project-oriented approaches it was planned to realize presidential priorities in modernization and other lines of operation of the foreign administrative apparatus of the Ministry of Economic Development of the Russian Federation (promotion of high-tech export and attraction of direct foreign investments) ${ }^{2}$.

However, a project-oriented approach aimed at achievement of concrete results in promotion of the interests of the national business on the global markets and which approach is inherent to foreign diplomatic and commercial missions of developed countries turned out to be unacceptable for most Russian TM due to complicated technical design assignments and the need to fill in planning maps and prepare business plans and multiple reports on them.

Project-oriented approaches successfully applied in corporate culture to operation conditions in the private sector happened to be unrequired and even detrimental (by virtue of excessive red tape) to government entities with conservative traditions. As a result, in implementation of projects traditional management methods in a "manual" mode rather than a systembased approach are normally utilized. It is to be noted that the emphasis is made on a prompt and spectacular effect, while the work aimed at achievement of long-term results is not often taken into account.

From 2013, an active stage began in realization of the Concept of Formation of a New Image of TM of the Russian Federation in Foreign States till $2016^{3}$ with an emphasis made on a customer-oriented approach. The key instruments of the above document were organization of business missions and preparation of passports of Russian projects which were facilitated in

1 See A. Pakhomov. The Strategy of Development of the Foreign Economic Complex / Issues of Theory and Practice of Management. 2010. No 12. pp. 18-29.

2 See Reports on Operations of the Ministry of Economic Development of the Russian Federation in respective years, the Web-site of the Ministry of Economic Development of the Russian Federation, http://www.economy.gov.ru

3 The document was approved on 13 March 2013 at the meeting of the Sub-Commission on Economic Integration of the Government Commission on Economic Development and Integration. the host country. So, a tilt to TM's commercial activities has taken place which situation is rather a strange one by virtue of the diplomatic status of TM and a lack of real instruments and qualified personnel for such work.

In the Soviet period, the system of the state monopoly on foreign trade formed the foundation of TM's effective operations, including in promotion of the export of the non-primary sectors. It envisaged the following:

- setting of mandatory performance indices (export plan, import plan and other);

- ensuring of TM's operations with adequate material and financial resources, including those in foreign currency;

- carrying out of business activities by over 60 specialized nationwide foreign trade associations whose representatives in TM fulfilled virtually all the commercial work;

- fulfillment of work by professional and highly motivated (materially) personnel which situation was justified by the elaborate system of training and, most importantly, job rotation of experts of the system of the USSR Ministry of Foreign Trade;

- fulfillment of work by several hundreds of fulltime experts and seconded employees which situation permitted to solve different and largescale objectives in a host country ${ }^{4}$.

In addition to the above, multiple staff of the economic advisor's offices (EAO) and the USSR State Committee on Economic Cooperation, including representative offices of 15 foreign economic associations (the Tyazhpromexport, the Atomenergoexport and other) worked simultaneously in dozens of developing countries under the auspices of the Foreign Trade Agency. EAO dealt with promotion and implementation of large-scale projects (normally in lieu of government loans) in the area of economic and R\&D cooperation with foreign states.

Analysis of the positive experience of TM of the Soviet period permits to identify the main components of their highly efficient work. They include the following: clear guidelines, adequate provision with the required resources, active work of specialized (intermediary) foreign trade entities, elaborate system of selection and rotation of personnel for working abroad and existence of multiple and skilled experts on the staff of TM.

4 For example, in the mid-1980s in Ethiopia the staff of TM (the Ministry of Foreign Trade) amounted to about 200 persons, while the Office of the Economic Advisor (the State Committee on Economic Cooperation), to 400 employees. At present, the Economic Department of the Russian Embassy in that country consists of only 3 employees. 
A comparative analysis has shown that almost all the above components either do not exist at present in the system of TM or are represented in a rather reduced format. It is to be noted that Russian TM do not demonstrate principally new components of efficiency. In addition to the above, the burden on TM personnel has largely increased due to opening of new lines of operations: interaction with regions, export support of small and mid-sized business and other.

It is to be noted that an important issue is training and selection and rotation of skilled personnel. The above measures may improve the quality of TM operations. At the same time, training of skilled personnel in the area of foreign economic affairs both at regional entities and small and mid-sized businesses is required. A successful implementation of that approach may yield a synergetic effect as at present the main customers of TM are representatives of the small and mid-sized business (the big business normally deals with its problems single handedly).

So, in present-day conditions of the market economy the set of foreign economic functions of TM has been radically changed and expanded, but it was not provided with the required information, administrative, material-technical, financial, regulatory and personnel resources. The leadership's numerous initiatives showed low practical efficiency because they were based solely on administrative or organizational measures and are to a great extent examples of the socalled "project-oriented approach" (and, eventually, a "manual mode of management").

It is those deep-rooted problems and differences as factors behind TM's low efficiency which the attention should be paid to. It is to be noted that ideologists of innovations did not virtually take into account those aspects. It appears that such an approach consists in the fact that some leaders have perceived TM as inferior (because there was virtually no feedback link) but self-sufficient agencies. However, trade missions are subordinate entities (though with a status of a legal entity) of the ministry in a narrow sense or components of Russia's foreign economic complex in a broad sense.

In addition to the above, it is important to take into account radical changes which have taken place in the global economy and, particularly, in the international trade from the beginning of the current decade: dramatic reduction of annual growth rates of global trade volumes and changes in their commodity and geographic flows. As a result, new centers of global economic growth emerged where Russia's presence is required $^{1}$.

1 For more details, see O. Biryukova and A. Pakhomov. The Results of Global Trade in Goods and Services in 2012 and the
At present, a main line of implementation of the New Image Concept deals with projects aimed at renewal of activities and establishment of new TM in different regions of the world ${ }^{2}$. In 2010, TM were opened up in Nicaragua and Abkhazia which situation with taking into account the economic potential of those countries can be regarded not only as a political decision, but also as the extent of influence of the Ministry of Foreign Affairs on issues of reforming the foreign administrative apparatus.

So, TM were reopened in Cuba and the Republic of South Africa only in 2014 and the practice showed that renewal of TM's activities in foreign states is a lengthy and costly process: negotiations with representatives of host countries, preparation of international agreements, as well as search for financial and material and technical resources required for proper functioning of new entities.

The Ministry of Economic Development of the Russian Federation has already prepared the list of countries where it plans to establish TM, but the expansion of the network is hindered due to the above factors. It is to be noted that establishment of new "outlets" can be sooner regarded as an extensive line of upgrading of trade missions' efficiency, rather than solution of their key problems.

Due to the above, it is expedient to study the international experience of developed countries' TM in dealing with different foreign trade agencies and link it to the Russian realities with mechanisms of further implementation and development envisaged. It appears that the US Commercial Service is one of the most effective agencies of that kind. It is to be noted that the US Administration is carrying out reforms of agencies and institutions of the foreign economic complex in order to adapt them to present-day realities of the global market ${ }^{3}$

The analysis of international practice provides a wide range of forms and ways of participation by the state in those entities, different sources of funding them and, most importantly, the set of functions aimed mainly at facilitation of foreign economic activities by national companies on global markets.

It is to be noted that various schemes of publicprivate partnership and outsourcing are feasible. TM of foreign states normally maintain close contacts with large non-government associations of entrepreneurs which have their own intermediary business entities.

Prospects of its Development / The Economic Development of Russia. 2013. Vol. 20. No. 5. pp. 14-19.

2 The Web-site of foreign economic information http://www. ved.gov.ru

3 «Obama requests Congressional authority to combine trade agencies», Inside US Trade, Wash., January 13, 2012. 
Such a mechanism permits to facilitate effectively commercial operations of national companies on third countries' markets.

With taking into account the Russian realities, at trade missions which are virtually in a transition stage it would be expedient to preserve mainly state functions of commercial and political nature and underpin them with relevant financial resources. Expansion of commercial competencies is feasible only on the basis of new forms of interaction with the domestic business up to establishment of nonstandard entities in host countries (commercial bureaus, merchant houses, cooperatives and other).

Apart from the quantitative criteria of growth in trade volumes and investments, evaluation of TM's operations should be based on the quality criteria, too (for example, promotion of the business image of Russia and, consequently, Russian companies). In addition to the above, reforms should be of an evolutionary nature, otherwise, as seen from the recent experience it is easy to lose traditional competences, but difficult to revive them.
It is believed that such measures as formation of an efficient structure of management of foreign economic affairs and hierarchy of its institutions, development of an elaborate personnel policy, motivation of employees, introduction of an effective system of performance standards, provision of professional services on a commercial basis to the business and separation of trade and political functions from commercial ones will permit Russia's TM abroad to become an effective instrument of new Russian foreign economic policy.

In the final analysis, it is important to understand that the problems and prospects of restructuring of TM represent inconsistencies in and limitations of functioning of Russia' foreign economic complex as a whole and its inadequate system of planning, management and regulation, in particular. So, tangible positive results in trade missions' activities can be expected only in case of reforms in Russia's foreign economic complex in general which is feasible only if foundations of a new economic model are formed in Russia. 